\title{
INTERACTIONS BETWEEN MENTAL HEALTH AND SOCIOECONOMIC STATUS IN THE SOUTH AFRICAN NATIONAL INCOME DYNAMICS STUDY
}

\author{
C Ardington and A Case*
}

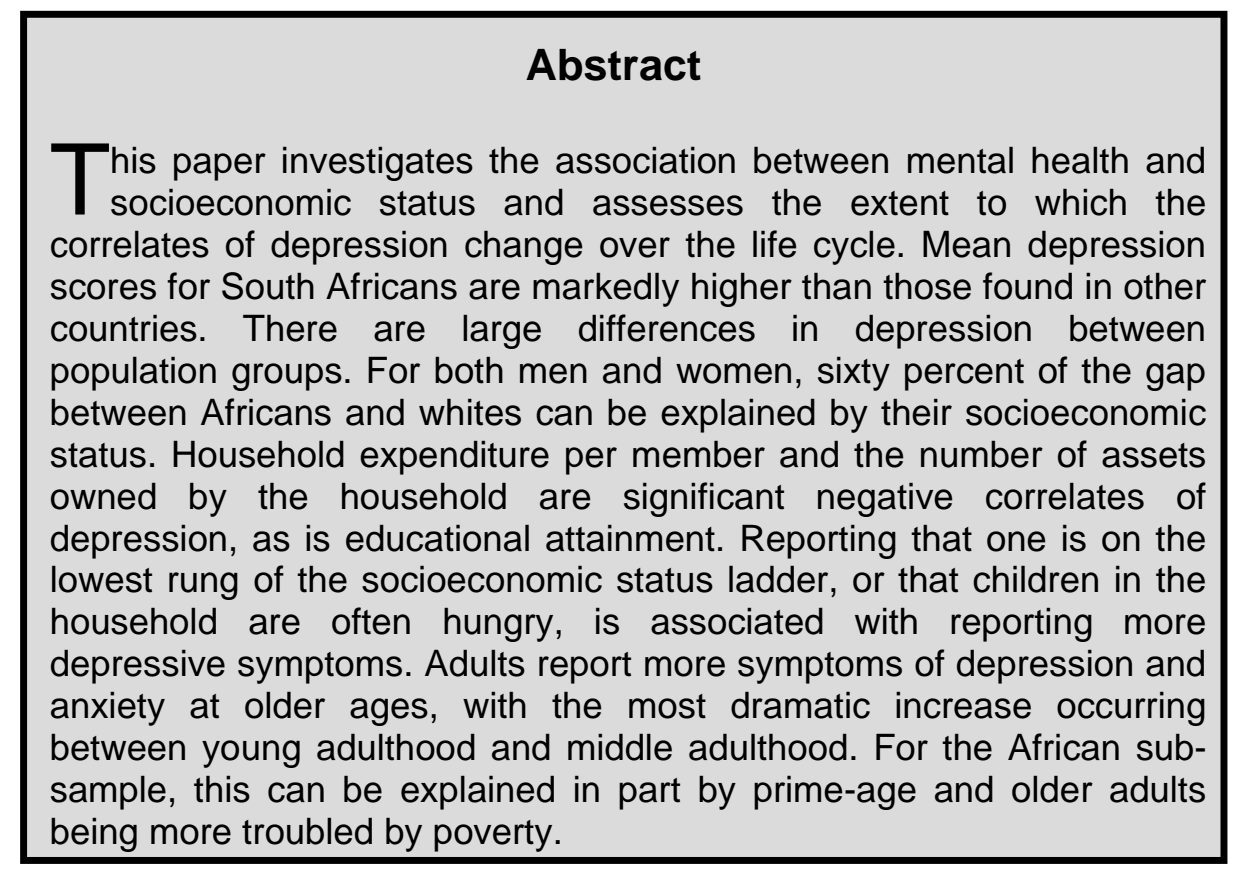

\section{Introduction}

Mental health, health status and socioeconomic status are important determinants of an individual's wellbeing. There are thought to be important interactions between these dimensions of wellbeing, with causal links running in both directions. Poor health and poor mental health can reduce earnings ability, through their effects on

\footnotetext{
* Respectively Senior Research Officer, Southern Africa Labour and Development Research Unit, University of Cape Town and Professor of Economics and Public Affairs at the Woodrow Wilson School of Public and International Affairs and the Economics Department at Princeton University. The authors acknowledge financial support for this paper from the Programme to Support Pro-poor Policy Development in the South African Presidency. Case acknowledges support from The Demography of Aging Center at Princeton University, funded under the National Institute of Aging grant P30 AG024361. Ardington acknowledges funding from the Fogarty International Center R01TW008661.

Email: cally.ardington@uct.ac.za
} 
education and employment, and poverty can lead to lower educational attainment, poorer physical health and depression.

Das et al. (2007) examine the correlates of mental health in five developing countries, finding that being older, female, widowed, and in poor physical health are consistently related to poorer mental health outcomes. However, their reading of their evidence on the relationship between socio-economic status (SES) and mental health is mixed. They find education to be positively associated with better mental health in a majority (but not all) of the countries that they study. Witoelar et al. (2009) analyse data from the fourth wave of the Indonesian Family Life Survey and find that education is protective against depression among Indonesians aged 45 and older but, controlling for education, they find no association between per capita expenditure and mental health for this group. A survey of 11 smaller community based studies in six low and middle income countries finds a negative association between education and common mental disorders in all but one study (Patel and Kleinman 2003). Results for other indicators of socioeconomic status such as employment and income were more mixed. In two localized South African studies, Case and Deaton (2009) find different aspects of SES protect in different ways: in their sites, education appears to protect health status, but has little effect on anxiety or depression, while assets protect against depression, but not against poor health.

One of the most consistent findings in the study of mental health in both developed and developing countries is that the risk of depression increases with age. Although the relationship between socioeconomic status and mental health has received considerable attention in the literature, particularly among the elderly, there is very little research that directly addresses whether the correlates of depression change as people grow older.

In this paper we present the first nationally representative descriptive account of the relationship between mental health and socioeconomic status in South Africa. The first wave of the National Income Dynamics Study (NIDS) included a battery of questions that allow for the construction of a depression index. This allows us to investigate which dimensions of socioeconomic status are associated with symptoms of depression and to assess the extent to which the importance of these determinants change over the life cycle.

We find mean depression scores for South Africans that are markedly higher than those found in other countries. Moreover, we find large differences in depression between population groups. Depression scores for African women are, on average, 43 percent higher than those found for white women, and scores for African men are 39 percent higher on average than those found for white men, with scores for coloured and Indian/Asian respondents falling between the white and African scores. For both men and women, sixty percent of the gap between Africans and whites can be explained by their socioeconomic status. Household expenditure per member and the number of assets owned by the household are significant negative correlates of depression, as is educational attainment. Reporting that one is on the lowest rung of the socioeconomic status ladder, or that children in the household are often hungry, is associated with reporting more depressive symptoms. Adults 
report more symptoms of depression and anxiety at older ages, with the most dramatic increase occurring between young adulthood and middle adulthood.

We document, for the African sub-sample, that this can be explained in part by prime-age and older adults being more troubled when children and adults in their households go hungry, and by being on the lowest step of the SES ladder, living in an urban informal area (as opposed to a rural area or formal urban area), and reporting lower household expenditure per person-all of which are markers of poverty. In addition, we find that education is protective of both physical health and household economic status-all of which is protective of mental wellbeing. The coefficient on education in a regression of the depression score on education is cut in half for Africans when indicators for self-assessed health, and chronic conditions are added to regressions that include SES markers, suggesting that physical health and economic wellbeing provide channels through which education is protective of mental health.

The paper is organized as follows. Section 2 describes the data from the first wave of NIDS. Section 3 presents age-adjusted regressions that allow comparisons of depression scores across population groups. Section 4 turns to the question of whether the correlates of depression change with age, focusing on the African subsample. Section 5 discusses the role of education, and Section 6 discusses implications of these findings.

\section{Data}

The National Income Dynamics Study (NIDS) is South Africa's first national panel survey. The project was initiated by the South African Presidency, and SALDRU at UCT was selected to conduct the first two waves of the study. Wave 1 was carried out in 2008, and the data were publically released for analysis in July 2009. In addition to a household questionnaire, an adult questionnaire was administered to every household member aged 15 and older, and the mother or primary caregiver completed a child questionnaire for household members aged $0-14$. In addition to other anthropometric measures, height and weight were measured for all respondents.

The overall household level response rate for Wave 1 was $69 \%$. In line with most South African household surveys, response rates were very low among white households (36\%). Response rates were $76 \%$ for African households, $73 \%$ for coloured households and 66\% for Indian/Asian households. Conditional on household response, individual response rates were encouraging with $93.3 \%$ of adult household members successfully interviewed (Leibbrandt, Woolard and de Villiers 2009).

The NIDS Adult questionnaire included the ten questions that make up the Center for Epidemiologic Studies Short Depression Scale (CES-D 10) (Radloff 1997). These questions ask whether certain feelings or behaviours occurred rarely or none of the time, some or a little of the time, occasionally or a moderate amount of the time, or all the time. The responses are scored and the CES-D 10 scale is the sum of 
these scores. This scale was not intended to determine the presence or absence of psychiatric disorders but rather "measures a continuum of psychological distress (symptoms of depression and anxiety) (Steffick 2000: 3)." In contexts where the CES-D has been validated, researchers often consider individuals with scores above a particular cut off as depressed (Eaton et al., 2004).

\section{Depression scores across population groups}

Table 1 shows the means and standard deviations of the CES-D 10 scores of NIDS respondents by population group and sex with results weighted by the poststratification weights. Mean depression scores among South African adults appear to be much higher than in other population based studies. For example, comparisons of similar age and gender groups result in South African CES-D scores that are roughly twice as large as those from the Indonesian Family Life Survey (Witoelar et al., 2009), the US Health and Retirement Study (Steffick 2000) and the Amsterdam Longitudinal Study of Aging (Hoogendijk et al., 2008). The prevalence in NIDS of certain feelings, such as depression and everything being an effort, is, however, similar to that for two small localised South African studiesone urban, one rural (Case and Deaton 2009). While the NIDS results may indicate a higher prevalence of depression in South Africa than in other countries, a number of cross-cultural validation studies have found that socio-cultural influences on emotional expression result in differing population mean CES-D scores (Eaton et al., 2000). Determining an appropriate cut off to indicate a high likelihood of depression in the South African context would require a supplementary validation exercise by mental health professionals. In this paper we therefore make no attempt to classify people as depressed but rather view the CES-D score as a continuum of symptoms of depression and anxiety. Our focus is on association between socioeconomic status, health status and poor mental health.

Table 1 shows that, on average, South African women report a greater number of symptoms of depression than do South African men. This gender gap is consistent with international evidence (Das et al., 2007, Van de Velde et al., 2010) and mirrors that of Case and Deaton (2009) in two smaller South African studies. For both men and women, mean depression scores are highest among Africans and lowest among whites.

The top left panel of Figure 1 shows that the risk of depression for both men and women increases with age. CES-D 10 scores increase sharply in young adulthood, flattening out in the early twenties for men and increasing more slowly for women between ages 25 and 40. At every age, women have higher average scores than men. The gender gap is narrowest in young adulthood and appears fairly consistent through prime age and older adulthood. With only one year of NIDS data, we cannot say whether the increase in the CES-D 10 score with age represents an ageor a birth-cohort-effect. Today's younger adults show fewer signs of depression than their elders currently. With additional years of data, it will be possible to track a given birth cohort over time, and document how depression scores in the birth cohort change. 
Table 1: Means, standard deviations and number of observations on CESD-10 depression scores by population group and sex

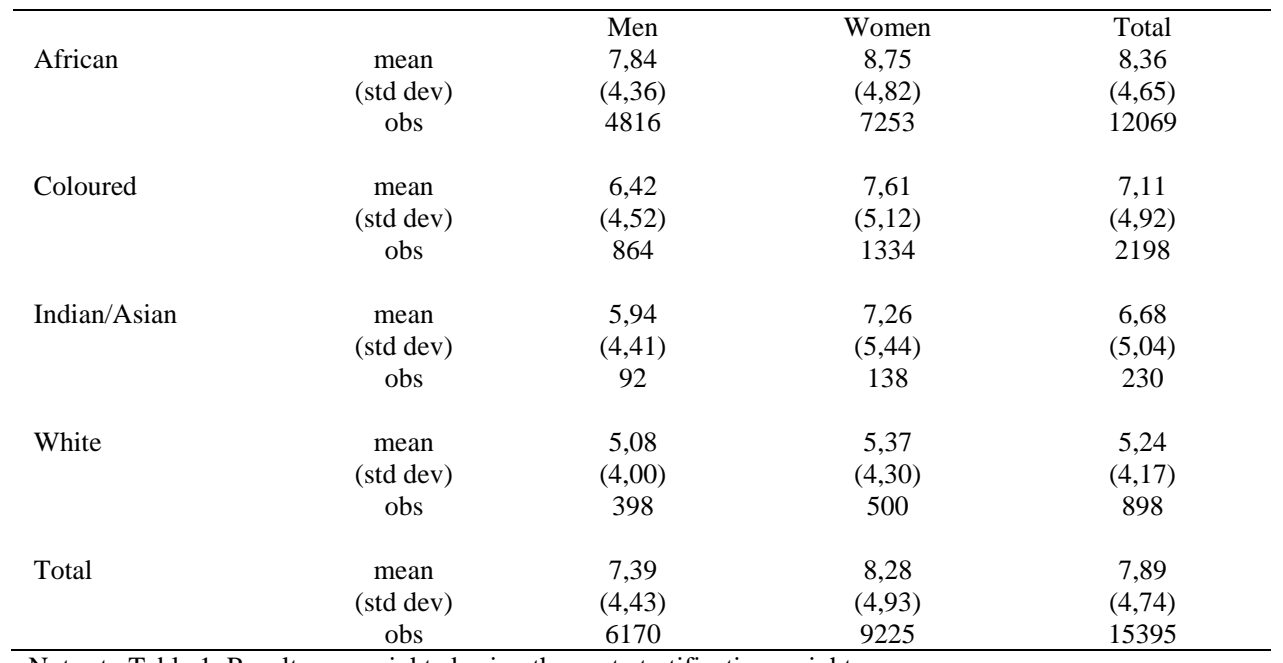

Notes to Table 1 . Results are weighted using the post-stratification weights

The next three panels of Figure 1 show the relationship between depression scores and three measures of socio-economic status, namely the logarithm of household expenditure per capita, a count of the assets that the household owns and years of completed education. A negative association between depression and socioeconomic status appears, with lower CES-D 10 scores among those with more education, from households with a greater number of assets and from households with higher per capita expenditure. The relationship with CES-D 10 scores is approximately linear for all three measures of socio-economic status. Indeed, the visual similarity between these associations is striking. The gender gap in CES-D 10 scores tends to be narrower at higher levels of socio-economic status.

Figure 2 shows the weighted age distribution of the NIDS sample by population group. The African sample is much younger than those of the other three main population groups with an average age of 35 years in contrast to an average age of 47 years for the white sample. Given the strong relationship between the CES-D 10 score and age in our sample, it is not informative to compare depression scores among population groups without first controlling for age. Similarly age is a confounding factor in assessing the association between depression and education. 


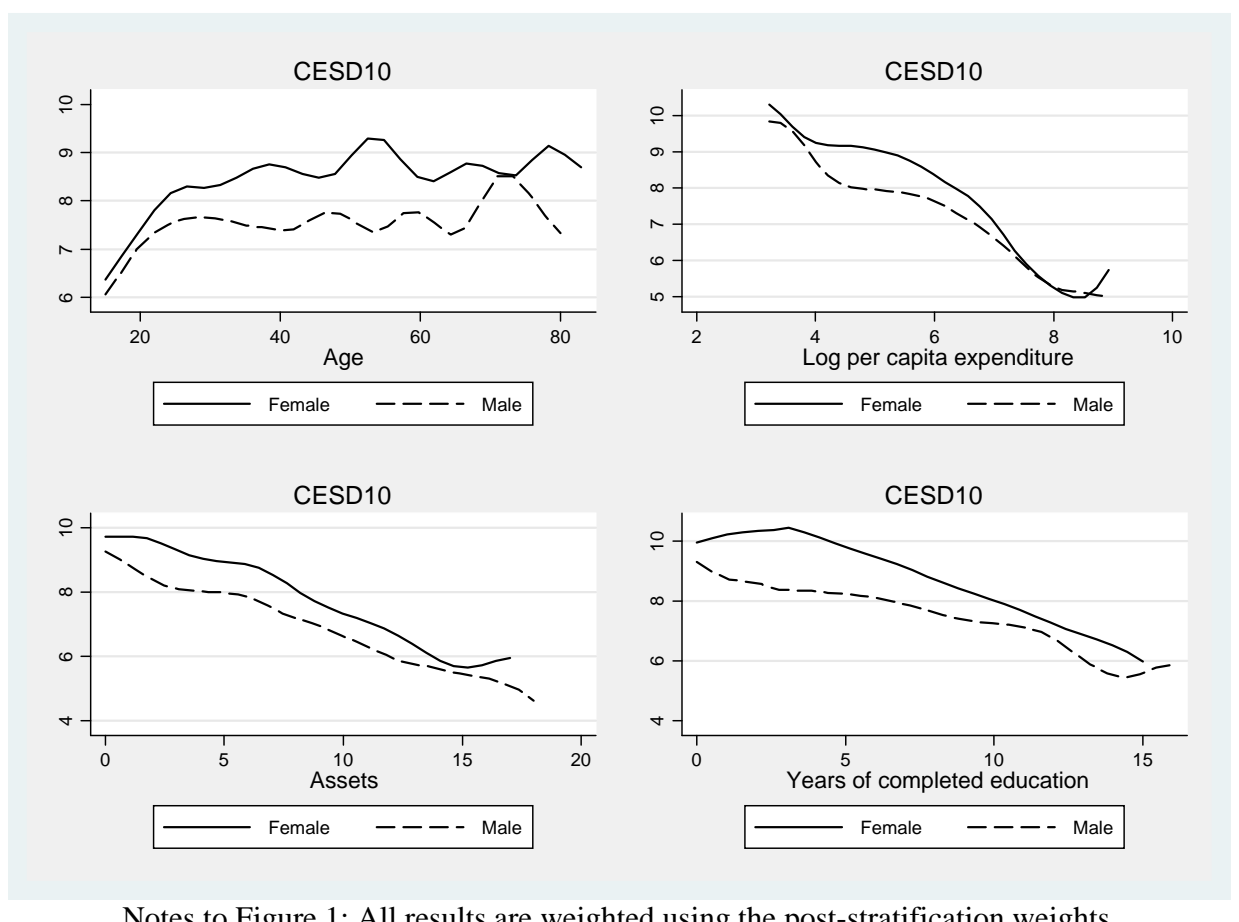

Figure 1: CES-D 10 depression score and age, logarithm of per capita expenditure, assets and years of completed education - South Africans aged 15 and older.

We therefore examine the determinants of the CES-D 10 score in a multivariate context where we can control for the confounding effect of age. Table 2 presents coefficients from ordinary least squares regressions that include a full set of indicators for age. Robust standard errors are presented in parentheses, where correlation has been allowed between unobservable variables for individuals from the same primary sampling unit. Regressions are run separately for men and women. The first regression shows that for both men and women, average CES-D 10 scores vary significantly by population groups with Africans having the highest score, followed by coloureds, then Indians/Asians and then whites. The magnitude of the differences is large with the average age adjusted score for African females 3.8 points (43 percent) higher than that of white females and African males 3.1 points (39 percent) higher than that of white males. The second regression includes two measures of household economic status: the logarithm of per capita household expenditure and a count of the number of household assets. As expected, given Figure 1, we find a negative relationship between economic status and symptoms of depression and anxiety. The inclusion of these economic status variables has a substantial effect on the coefficients for population groups. The coefficients for Indian/Asian and for coloured are no longer statistically significant, and the white coefficient is cut by sixty percent. Additional controls for socioeconomic status are also statistically significant (columns 3 and 6). Both women and men report fewer depression symptoms when they have more years of education, on average. Women report more depression symptoms when children in their households often or 
always go hungry. Men report more symptoms when they perceive themselves on the bottom step of a six step SES ladder. While these add to the evidence that depression is highly correlated with SES in South Africa, their inclusion does little to further close the gap between African and white reports of depression.

Table 2: CES-D 10 score, population group and economic status for South Africans aged 15 and older

\begin{tabular}{|c|c|c|c|c|c|c|}
\hline \multirow[b]{2}{*}{ Coloured } & \multicolumn{3}{|c|}{ Women } & \multicolumn{3}{|c|}{ Men } \\
\hline & $\begin{array}{c}-1,336 * * * \\
(0,451)\end{array}$ & $\begin{array}{l}-0,559 \\
(0,426)\end{array}$ & $\begin{array}{l}-0,645 \\
(0,408)\end{array}$ & $\begin{array}{c}-1,250^{* * *} \\
(0,377)\end{array}$ & $\begin{array}{c}-0,609^{*} \\
(0,336)\end{array}$ & $\begin{array}{c}-0,620^{*} \\
(0,321)\end{array}$ \\
\hline Indian/Asian & $\begin{array}{c}-1,544 * * \\
(0,783)\end{array}$ & $\begin{array}{c}0,142 \\
(0,759)\end{array}$ & $\begin{array}{c}0,047 \\
(0,773)\end{array}$ & $\begin{array}{c}-1,743^{* *} \\
(0,799)\end{array}$ & $\begin{array}{l}-0,374 \\
(0,664)\end{array}$ & $\begin{array}{l}-0,455 \\
(0,681)\end{array}$ \\
\hline White & $\begin{array}{c}-3,877^{* * *} \\
(0,440)\end{array}$ & $\begin{array}{c}-1,656^{* * *} \\
(0,526)\end{array}$ & $\begin{array}{c}-1,513^{* * * *} \\
(0,522)\end{array}$ & $\begin{array}{c}-3,188^{* * * *} \\
(0,313)\end{array}$ & $\begin{array}{c}-1,346^{* * *} \\
(0,478)\end{array}$ & $\begin{array}{c}-1,274 * * * \\
(0,463)\end{array}$ \\
\hline $\begin{array}{l}\text { Log expenditure per } \\
\text { member }\end{array}$ & - & $\begin{array}{c}-0,422 * * * \\
(0,114)\end{array}$ & $\begin{array}{c}-0,397^{* * * *} \\
(0,118)\end{array}$ & -- & $\begin{array}{c}-0,525^{* * * *} \\
(0,096)\end{array}$ & $\begin{array}{c}-0,428 * * * \\
(0,098)\end{array}$ \\
\hline Assets & -- & $\begin{array}{c}-0,160 * * * \\
(0,035)\end{array}$ & $\begin{array}{c}-0,114^{* * *} \\
(0,035)\end{array}$ & -- & $\begin{array}{c}-0,105^{* * *} \\
(0,026)\end{array}$ & $\begin{array}{c}-0,078^{* * *} \\
(0,027)\end{array}$ \\
\hline Years education & -- & -- & $\begin{array}{c}-0,078^{* * *} \\
(0,028)\end{array}$ & -- & -- & $\begin{array}{c}-0,059^{* *} \\
(0,024)\end{array}$ \\
\hline $\begin{array}{l}\text { Male pensioner } \\
\text { household }\end{array}$ & -- & -- & $\begin{array}{c}-0,885^{* *} \\
(0,288)\end{array}$ & -- & -- & $\begin{array}{l}-0,028 \\
(0,498)\end{array}$ \\
\hline $\begin{array}{l}\text { Female pensioner } \\
\text { household }\end{array}$ & -- & -- & $\begin{array}{l}-0,026 \\
(0,287)\end{array}$ & -- & -- & $\begin{array}{c}0,341 \\
(0,317)\end{array}$ \\
\hline Poorest household & -- & -- & $\begin{array}{c}0,592 \\
(0,405)\end{array}$ & -- & -- & $\begin{array}{c}0,956 * * * \\
(0,352)\end{array}$ \\
\hline $\begin{array}{l}\text { Children hungry in } \\
\text { household }\end{array}$ & -- & -- & $\begin{array}{c}1,891 * * * \\
(0,579)\end{array}$ & -- & -- & $\begin{array}{c}0,887 \\
(0,590)\end{array}$ \\
\hline Constant & $\begin{array}{c}8,915 * * * \\
(0,137)\end{array}$ & $\begin{array}{c}12,080^{* * *} \\
(0,580)\end{array}$ & $\begin{array}{c}12,175^{* * *} \\
(0,592)\end{array}$ & $\begin{array}{c}7,884^{* * *} \\
(0,140)\end{array}$ & $\begin{array}{c}11,426^{* * *} \\
(0,553)\end{array}$ & $\begin{array}{c}11,024 * * * \\
(0,557)\end{array}$ \\
\hline $\begin{array}{l}\text { F-test SES variables } \\
\text { (p-value) }\end{array}$ & -- & $\begin{array}{c}26,63 \\
(0,000)\end{array}$ & $\begin{array}{l}11,76 \\
(0,000)\end{array}$ & -- & $\begin{array}{l}26,16 \\
(0,000)\end{array}$ & $\begin{array}{c}10,07 \\
(0,000)\end{array}$ \\
\hline Observations & 7148 & 7148 & 7109 & 4927 & 4927 & 4888 \\
\hline
\end{tabular}

As discussed earlier, there is evidence of cross-cultural differences in CES-D 10 scores (Eaton et al., 2000, Long Foley 2002). Indeed, an examination of the components of the index suggests differences in the expression of positive affect between population groups in South Africa. This, then, supports an approach of examining each population group separately. In what follows, we restrict our focus to Africans for two reasons. The sample size of the other three population groups does not allow for an analysis disaggregated by age and sex. In addition, high refusal rates, among whites in particular, raise concerns around selection bias. 


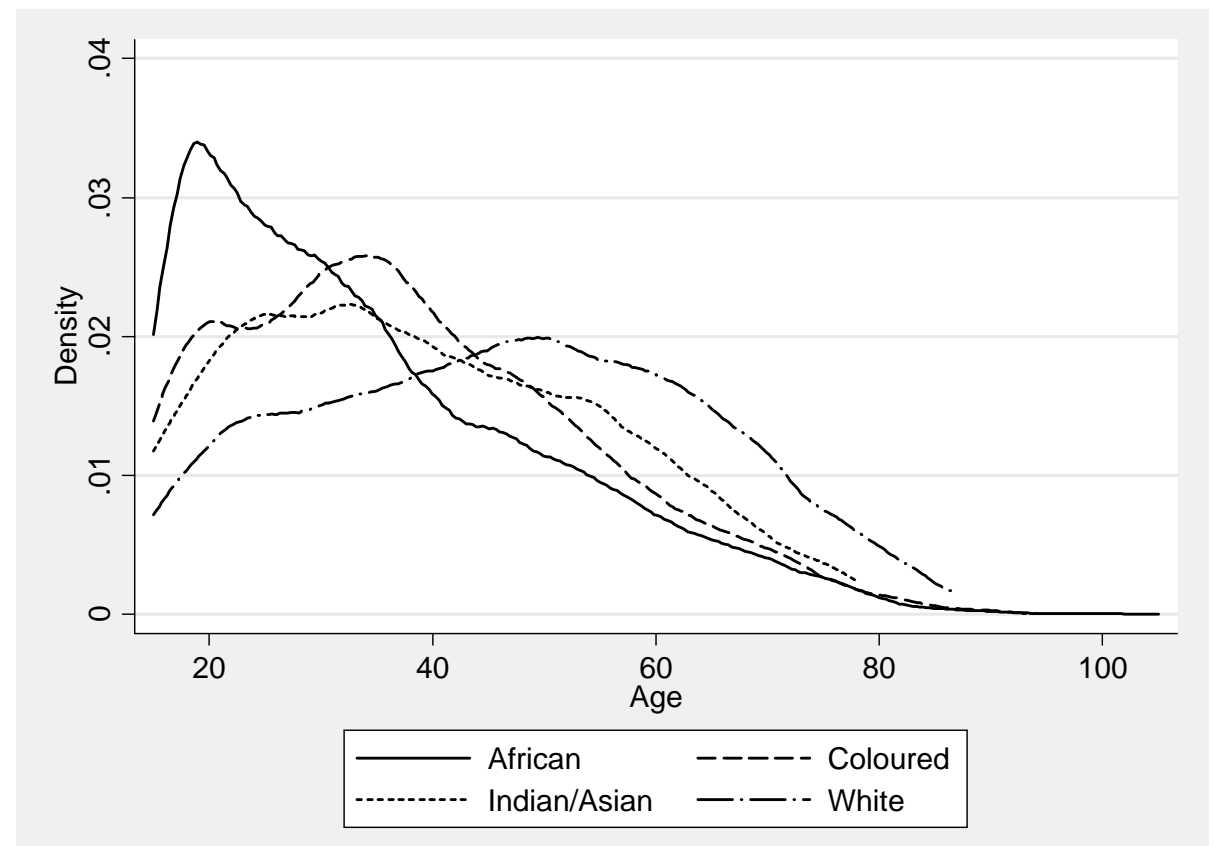

Notes to Figure 2: All results are weighted using the post-stratification weights.

Figure 2: Age distribution by population group - South Africans aged 15 and older

\section{Depression correlates across age groups}

Figure 1 shows that South Africans are at greater risk of depression at older ages. In this section, we examine the extent to which personal and household characteristics matter for mental wellbeing and importantly, whether these correlates of mental wellbeing change over the life cycle. We divide our sample into three groups, namely young adults (aged 15 to 24), prime-age adults (aged 25 to 49) and older adults (aged 50 and older). Table 3 presents descriptive statistics for these three groups on a range of measures of health status, personal and household socioeconomic status, and self-rated poverty status.

Our set of health variables is composed of an indicator that respondents report themselves to be in fair or poor health, an indicator that they have at least one chronic condition, and the number of activities of daily living with which they report having difficulty. Respondents were asked to describe their current health on a five point scale where one is excellent and five is poor. Overall, $18 \%$ of respondents classified themselves to be in fair or poor health. Women and older people tend to report worse health, which follows a pattern observed in many countries (Case and Paxson 2005). Respondents were asked if they had ever been told by a health care professional that they had each of a list of chronic illnesses. The percentage of respondents who report that they have at least one chronic condition increases with age and tends to be higher for women than men. NIDS included questions about limitations in carrying out a range of 11 activities from dressing and bathing to carrying and lifting heavy objects. As expected, the mean 
number of activities of daily living (ADL) for which the respondent reports having any sort of difficulty (they can do with difficulty, can do only with help or can't do) increase with age. On average, women tend to report a greater number of limitations at every age.

On personal socioeconomic status, we focus on years of completed education. The legacy of apartheid is very clear in the striking variation in years of completed education by age group. Young adults have on average more than twice as many years of completed education as older adults. Consistent with the South African literature on education (Anderson, Case and Lam 2001), aside from the older adults, women tend to have marginally more years of education than men.

Table 3: Individual and household characteristics for Africans aged 15 years and older

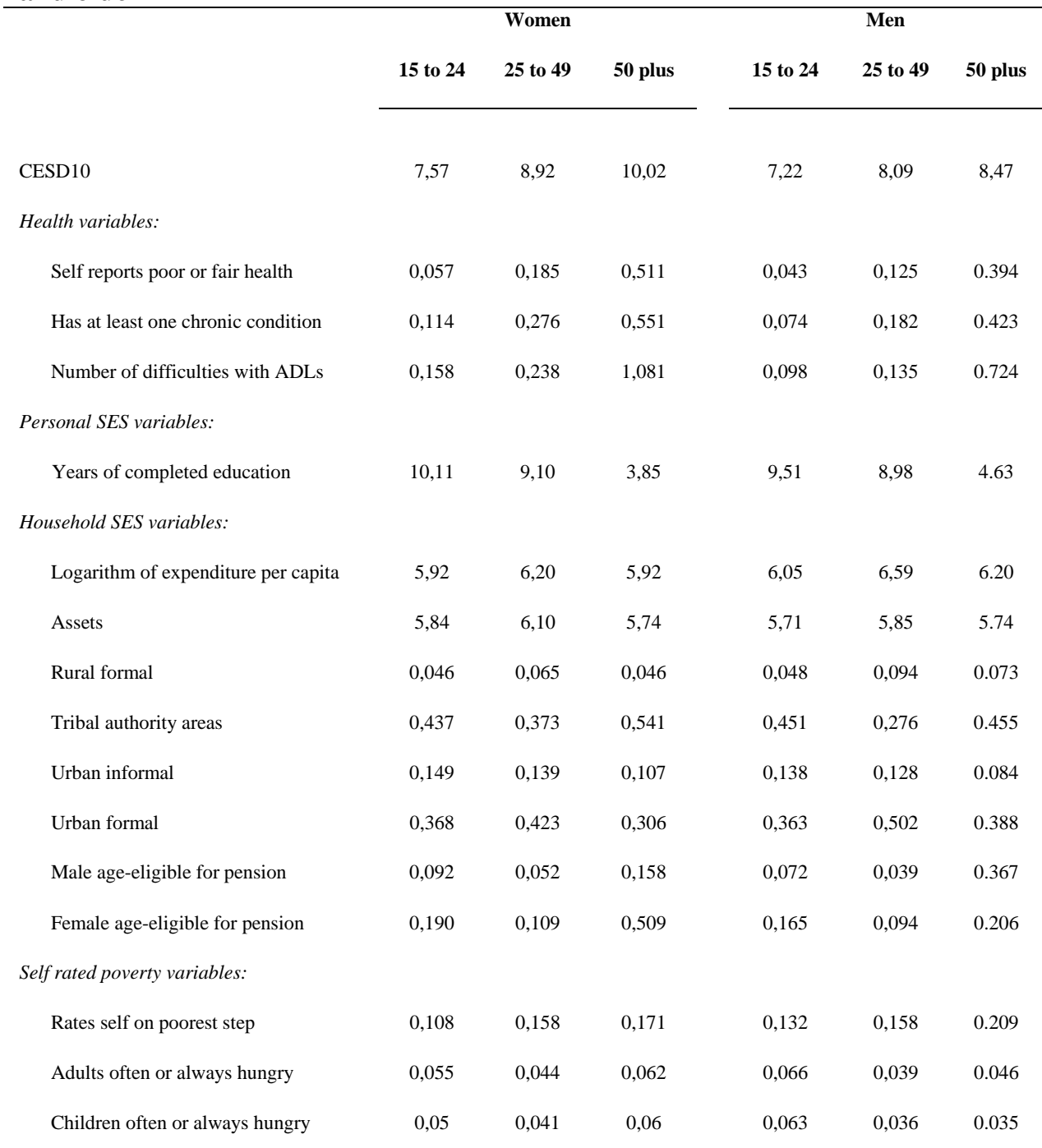


Notes to Table 3: All results are weighted using post-stratification weights

Our household SES variables include the logarithm of per capita expenditure, ${ }^{1}$ a count of household assets, indicators that there is at least one male (female) who is age-eligible for the state old age pension and indicators for the type of enumeration area (rural formal, traditional authority area, urban informal and urban formal).

NIDS included a number of questions that probe self perceptions of poverty. Respondents were asked to place themselves on a six step ladder with the poorest people in South Africa on the bottom step and the richest on the top step. Overall $15 \%$ of Africans rated themselves on the poorest step. The other measures of self assessed poverty were asked at the household level and concern food security. Around $5 \%$ of respondents live in households where adults often or always went hungry. A slightly smaller percentage live in households where children often or always went hungry.

Table 4 examines whether correlates of depression are different by age group. Separately for women and men, we regress the CES-D 10 score on a variable thought to be associated with depression-here education, log expenditure per household member, assets owned by the household, reports of being on the bottom step of the socioeconomic ladder, reports of adults in the household often or always being hungry, and reports of children in the household often or always being hungry. Each column comes from a different regression in which the CES-D 10 score is regressed on the variable listed at the top of the column, and that variable interacted with whether the respondent was aged 25-49, and a second interaction of that variable with whether the respondent was aged 50 or above. A complete set of indicators for age was included in each regression. Standard errors appear beneath the regression coefficients. These are calculated allowing for correlation in the unobservables for individuals drawn from the same primary sampling unit. Regressions are weighted using the post stratification weights provided by NIDS.

In these regressions, the 'main effect' refers to the association between the variable named in the top row and the CES-D 10 reports for Africans aged 15 to 24. For example, assets held by the household are negatively and significantly associated with CES-D 10 scores for both men and women. For each woman aged 15 to 24, each additional asset is associated with a reduction in the CES-D 10 score of 0,18 points, on average, and for men in that age group, a reduction of 0,15 points. To calculate the impact for women aged 25 to 49 , we need to add that original coefficient to the interaction coefficient estimated for women 25 to 49. In the case of assets, neither this interaction term, nor that for women aged 50 or above is

\footnotetext{
${ }^{1}$ NIDS provides a range of total household expenditure variables. We use the measure of total household expenditure that aggregates all expenditure categories but does not include imputations for missing values. Results do not change in any substantive way if we include imputed values. However, we are concerned that measurement error induced by imputing values may lead to an underestimate of the variable's importance. This led us to use the more conservative measure of expenditure per capita.
} 
significantly different from zero - which suggests that deprivation in this dimension is uniform over age categories. For women, the same is true for the association between depression and the log expenditure per household member. In contrast, placement on the lowest rung of an SES ladder for individuals aged 15 to 24 is not correlated with their CES-D 10 score. However, for adults aged 25 to 49, assessing themselves on the lowest rung is associated with at 1,5 point increase in their depression index $(0,492+1.048)$, and for those age 50 and older, the bottom rung is associated with an increase in their depression score of $1,25(0,492+0,751)$. Similar results are seen for men: there is no significant increase in the depression scores of men aged 15 to 24 if they perceive themselves to be on the lowest rung. However, for men at ages 50 or above, for example, this self-perception of poverty is associated with an increase in the depression index of 1,9. For both men and women, the correlation of depression with perceiving oneself on the lowest rung of an SES ladder, and household reports that children go hungry and, separately, that adults go hungry, is stronger at older ages.

Table 4: Changes in the correlates of depression with age

\begin{tabular}{|c|c|c|c|c|c|c|}
\hline & \multicolumn{6}{|c|}{ Women } \\
\hline & \multicolumn{6}{|c|}{ Coefficient of this variable in CESD-10 regression: } \\
\hline & Education & $\begin{array}{l}\text { Log expend } \\
\text { per member }\end{array}$ & Assets & Poorest & Adult hungry & Child hungry \\
\hline Main effect & $\begin{array}{c}-0,264 * * * \\
(0,081)\end{array}$ & $\begin{array}{c}-0,527^{* * *} \\
(0,172)\end{array}$ & $\begin{array}{c}-0,175 * * * \\
(0,047)\end{array}$ & $\begin{array}{c}0,492 \\
(0,386)\end{array}$ & $\begin{array}{c}0,698 \\
(0,575)\end{array}$ & $\begin{array}{c}0,943 \\
(0,656)\end{array}$ \\
\hline$\times$ age $25-49$ & $\begin{array}{c}0,035 \\
(0,084)\end{array}$ & $\begin{array}{l}-0,313 \\
(0,209)\end{array}$ & $\begin{array}{l}-0,062 \\
(0,048)\end{array}$ & $\begin{array}{l}1,048^{*} \\
(0,552)\end{array}$ & $\begin{array}{c}2,024 * * * \\
(0,683)\end{array}$ & $\begin{array}{c}1,864 * * \\
(0,744)\end{array}$ \\
\hline$\times$ age $50+$ & $\begin{array}{c}0,222 * * \\
(0,087)\end{array}$ & $\begin{array}{c}0,303 \\
(0,259)\end{array}$ & $\begin{array}{l}-0,023 \\
(0,057)\end{array}$ & $\begin{array}{c}0,751^{* *} \\
(0,621)\end{array}$ & $\begin{array}{c}2,423 * * * \\
(0,780)\end{array}$ & $\begin{array}{c}2,662^{* * *} \\
(0,871)\end{array}$ \\
\hline Observations & \multicolumn{6}{|c|}{ Men } \\
\hline Main effect & $\begin{array}{c}-0,111^{*} \\
(0,058)\end{array}$ & $\begin{array}{c}-0,457 * * * \\
(0,150)\end{array}$ & $\begin{array}{c}-0,148 * * * \\
(0,039)\end{array}$ & $\begin{array}{c}0,630 \\
(0,406)\end{array}$ & $\begin{array}{l}-0,011 \\
(0,447)\end{array}$ & $\begin{array}{c}0,134 \\
(0,477)\end{array}$ \\
\hline$\times$ age $25-49$ & $\begin{array}{l}-0,054 \\
(0,070)\end{array}$ & $\begin{array}{l}-0,156 \\
(0,210)\end{array}$ & $\begin{array}{l}-0,022 \\
(0,061)\end{array}$ & $\begin{array}{l}1,082^{*} \\
(0,625)\end{array}$ & $\begin{array}{c}3,484 * * * \\
(1,323)\end{array}$ & $\begin{array}{c}2,820^{* *} \\
(1,250)\end{array}$ \\
\hline$\times$ age $50+$ & $\begin{array}{l}-0,075 \\
(0,083)\end{array}$ & $\begin{array}{c}-0,501^{* *} \\
(0,230)\end{array}$ & $\begin{array}{l}-0,053 \\
(0,057)\end{array}$ & $\begin{array}{c}1,277^{* * *} \\
(0,616)\end{array}$ & $\begin{array}{c}3,534 * * * \\
(1,123)\end{array}$ & $\begin{array}{c}3,483 * * * \\
(1,577)\end{array}$ \\
\hline Observations & 4779 & 3860 & 4796 & 4770 & 4779 & 4796 \\
\hline
\end{tabular}

Notes to Table 4: Each column reports coefficients from a regression of the CES-D 10 score on the variable listed in the top row of the table, and that variable interacted with an indicator that the individual was between 25 and 49 years old, and that variable interacted with an indicator that age was 50 or above. Robust standard errors are presented in parenthesis. Correlation has been allowed between unobservables for individuals living in the same primary sampling unit. Regressions were weighted using post-stratification weights. All regressions included a complete set of indicators for age in years, and regressions in the last column also include an indicator that child hunger was missing (true if there were no children in the household). ${ }^{* *} \mathrm{p}<0,01,{ }^{* *} \mathrm{p}<0,05,{ }^{*} \mathrm{p}<0,10$.

There are several non-competing explanations for the stronger impact of economic deprivation at older ages on CES-D 10 scores. It is possible that poverty has a cumulative effect on mental health so that older adults, who may have shouldered economic burdens for a longer period, may have had their mental health diminished more than younger adults. Alternatively, it has been well documented that younger adults tend to be more optimistic about their futures, even when that optimism is not well grounded.

Table 5 examines whether depression scores are significantly different between age groups of men and women, depending on where they are resident - that is, in urban informal areas, urban formal areas, or traditional rural areas - all relative to rural formal residence. Again, a complete set of indicators for age was included in each 
regression. Standard errors appear beneath the regression coefficients. These are calculated allowing for correlation in the unobservables for individuals drawn from the same primary sampling unit. Regressions are weighted using the post stratification weights provided by NIDS. Table 5 suggests that younger adults those aged 15 to 24 - are not significantly affected by whether they live in rural or urban formal or informal areas. None of the 'main effect' coefficients - which are those for youngest adults - are statistically significant. However, women aged 25 to 49 report significantly more symptoms of depression on average when they live in urban informal areas, and women aged 50 and above express even more depressive symptoms when interviewed in urban informal areas. The same is true for men aged 50 and above. Urban informal areas include the shack townships that surround most major cities. These results suggest that two sisters - one in Khayelitsha outside of Cape Town and one in Lilydale in Limpopo (a formal rural area) - would on average report different depression scores, with the former higher than the latter.

Table 5: Residency and depression

\begin{tabular}{|c|c|c|}
\hline & Women & Men \\
\hline \multicolumn{3}{|l|}{ Urban informal: } \\
\hline Main effect & $\begin{array}{l}-0,329 \\
(0,667)\end{array}$ & $\begin{array}{c}0,578 \\
(0,963)\end{array}$ \\
\hline \multirow[t]{2}{*}{$\times$ age $25-49$} & $1,674^{*}$ & $-0,157$ \\
\hline & $(0,911)$ & $(0,885)$ \\
\hline \multirow[t]{2}{*}{$\times$ age $50+$} & $2,397^{*}$ & $2,241^{*}$ \\
\hline & $(1,265)$ & $(1,173)$ \\
\hline \multicolumn{3}{|l|}{ Urban formal: } \\
\hline \multirow[t]{2}{*}{ Main effect } & $-0,065$ & $-0,159$ \\
\hline & $(0,511)$ & $(0,737)$ \\
\hline \multirow{2}{*}{$\times$ age $25-49$} & $-0,467$ & 0,685 \\
\hline & $(0,605)$ & $(0,842)$ \\
\hline \multirow{2}{*}{$\times$ age $50+$} & $-0,487$ & $-0,286$ \\
\hline & $(0,731)$ & $(0,804)$ \\
\hline \multicolumn{3}{|c|}{ Traditional authority: } \\
\hline \multirow[t]{2}{*}{ Main effect } & $-0,092$ & 0,135 \\
\hline & $(0,473)$ & $(0,729)$ \\
\hline \multirow[t]{2}{*}{$\times$ age $25-49$} & 0,601 & 1,085 \\
\hline & $(0,610)$ & $(0,849)$ \\
\hline \multirow[t]{2}{*}{$\times$ age $50+$} & $-0,033$ & 0,983 \\
\hline & $(0,695)$ & $(0,722)$ \\
\hline \multirow[t]{2}{*}{ Constant } & $8,698 * * *$ & $7,401 * * *$ \\
\hline & $(0,286)$ & $(0,391)$ \\
\hline Observations & 7196 & 4796 \\
\hline \multicolumn{3}{|c|}{$\begin{array}{l}\text { Notes to Table } 5 \text {. Each column reports coefficients from a regression of the CES-D } 10 \text { score on an indicator } \\
\text { for residency in an urban informal area, an urban formal area or a traditional authority area, with the omitted } \\
\text { category being residency in a rural formal area. The 'main effect' for each variable reports results for adults } \\
15 \text { to } 24 \text {. Also included are interactions of residency indicators with an indicator that the individual was } \\
\text { between } 25 \text { and } 49 \text { years old, and these residency indicators interacted with an indicator that age was } 50 \text { or } \\
\text { above. Robust standard errors are presented in parenthesis. Correlation has been allowed between } \\
\text { unobservables for individuals living in the same primary sampling unit. Regressions were weighted using } \\
\text { post-stratification weights. All regressions included a complete set of indicators for age in years. } \\
{ }^{* * *} \mathrm{p}<0,01,{ }^{* *} \mathrm{p}<0,05,{ }^{*} \mathrm{p}<0,10 \text {. }\end{array}$} \\
\hline
\end{tabular}

Overall, we find evidence that correlates of poverty - particularly assessment of poor socioeconomic status, reports of child and adult hunger, and residency in 
urban informal areas - are stronger among older adults (25 to 49), and strongest among adults aged 50 and older. 


\section{Education and depression}

Educational attainment appears as a robust correlate of depression in the NIDS data. ${ }^{2}$ Here, we examine the health and socioeconomic status mechanisms through which education may affect mental health. Table 6 examines the possible role of education in several outcomes - reporting oneself in 'fair' or 'poor' health (in contrast to 'excellent' 'very good' or 'good' health); an indicator that one reports at least one chronic health condition; that one reports difficulties with activities of daily living; that one reports being on the lowest rung of the SES ladder; and the household reporting child hunger; adult hunger; and log expenditure per household member. There is a large literature establishing that education may be protective of health, after the mechanisms that are responsible for disease control are understood. ${ }^{3}$ We examine this in Table 6, where we report, for men and women separately, the coefficients of years of education in a regression of these potential influences on mental health. A complete set of indicators for age was included in each regression. Standard errors appear beneath the regression coefficients. These are calculated allowing for correlation in the unobservables for individuals drawn from the same primary sampling unit. Regressions are weighted using the post stratification weights provided by NIDS. With one exception - an indicator for chronic conditions for men - we find that years of education appear to be protective for health, chronic conditions, difficulties with activities of daily living, and with SES measures such as adult hunger, child hunger, reporting being on the lowest rung, and household spending using the log expenditure per member.

Table 6: Education, health and socioeconomic status

\begin{tabular}{|c|c|c|c|c|c|c|c|}
\hline & \multicolumn{7}{|c|}{ Dependent variable: } \\
\hline & Poor health & $\begin{array}{l}\text { Chronic } \\
\text { condition }\end{array}$ & $\begin{array}{c}\text { ADL } \\
\text { difficulties }\end{array}$ & $\begin{array}{c}\text { Child hunger } \\
\text { Women }\end{array}$ & Adult hunger & $\begin{array}{c}\text { Poorest } \\
\text { household }\end{array}$ & $\begin{array}{l}\text { Log expend per } \\
\text { member }\end{array}$ \\
\hline $\begin{array}{l}\text { Years of } \\
\text { education } \\
\text { Observations }\end{array}$ & $\begin{array}{c}-0,016^{* * * *} \\
(0,002) \\
7164\end{array}$ & $\begin{array}{c}-0,008^{* * * *} \\
(0,002) \\
7110\end{array}$ & $\begin{array}{c}-0,019 * * * \\
(0,005) \\
7203\end{array}$ & $\begin{array}{c}-0,005^{* * * *} \\
(0,001) \\
6359\end{array}$ & $\begin{array}{c}-0,007 * * * \\
(0,001) \\
7183\end{array}$ & $\begin{array}{c}-0,015^{* * * *} \\
(0,002) \\
7165\end{array}$ & $\begin{array}{c}0,100^{* * * *} \\
(0,008) \\
5631\end{array}$ \\
\hline & & & & Men & & & \\
\hline $\begin{array}{l}\text { Years of } \\
\text { education }\end{array}$ & $\begin{array}{c}-0,013^{* * *} \\
(0,002)\end{array}$ & $\begin{array}{l}-0,003 \\
(0,002)\end{array}$ & $\begin{array}{c}-0,023 * * * \\
(0,007)\end{array}$ & $\begin{array}{c}-0,004 * * * \\
(0,001)\end{array}$ & $\begin{array}{c}-0,006^{* * *} \\
(0,001)\end{array}$ & $\begin{array}{c}-0,015 * * * \\
(0,002)\end{array}$ & $\begin{array}{c}0,095 * * * \\
(0,010)\end{array}$ \\
\hline Observations & 4766 & 4742 & 4801 & 3647 & 4783 & 4761 & 3863 \\
\hline
\end{tabular}

Notes to Table 6. Each column reports coefficients from a regression of a health or socioeconomic status outcome on years of completed same primary sampling unit. Regressions were weighted using post-stratification weights. All regressions included a complete set of indicators for age in years. ${ }^{* * *} \mathrm{p}<0,01,{ }^{* *} \mathrm{p}<0,05,{ }^{*} \mathrm{p}<0,10$

\footnotetext{
${ }^{2}$ The exception here is for African women aged 50 or older. For these women, educational attainment was so low (mean years of education are 3,9 years for this group) and would have been of such variable quality that it is not surprising that is does not stand as a significant correlate of mental health.

${ }^{3}$ Preston (1996), for example, notes that in 1900, the mortality risk for a school teacher's child in the US was no better than that of the average child. However, by 1925, once the germ theory of disease was well accepted, school teachers' children's survival rates were dramatically better than that for the average child. Feldman et al. (1989) document that in 1960 there was little difference in middle-age or old-age mortality rates for men by educational attainment. However, 20 years later, once the risks associated with smoking were better understood, better educated men's mortality risks were significantly and substantially lower than their less well educated counterparts.
} 
We use this information to assess the impact of education on our depression index. Table 7 shows that education, for the whole sample and for the sample for which we have a complete set of covariates, is negatively and significantly associated with our depression scores for men and women. There are no significant differences in the coefficients on education for the whole sample, for men and women separately, and those for which we have covariates. On average, without additional controls, an additional year of education is associated with a reduction in the CES-D 10 score of 0,16 and 0,18 points for African men and women respectively. In trying to assess how education may work, we then add to the regression several health and socioeconomic status variables. Their addition reduces the impact of education by more than 50 percent, and suggests that these are channels which, in the future, we should follow to better understand the relationship between mental health and economic status.

Table 7: Depression and education

\begin{tabular}{|c|c|c|c|c|c|c|}
\hline \multirow[b]{2}{*}{ Years of education } & \multicolumn{3}{|c|}{ Women } & \multicolumn{3}{|c|}{ Men } \\
\hline & $\begin{array}{c}-0,179 * * * \\
(0,027)\end{array}$ & $\begin{array}{c}-0,171^{* * * *} \\
(0,029)\end{array}$ & $\begin{array}{c}-0,067^{* *} \\
(0,028)\end{array}$ & $\begin{array}{c}-0,161^{* * * *} \\
(0,026)\end{array}$ & $\begin{array}{c}-0,153^{* * * *} \\
(0,028)\end{array}$ & $\begin{array}{c}-0,074^{* * *} \\
(0,026)\end{array}$ \\
\hline Poor health & -- & - & $\begin{array}{c}1,032^{* * *} \\
(0,314)\end{array}$ & -- & - & $\begin{array}{c}1,084 * * * \\
(0,339)\end{array}$ \\
\hline Chronic conditions & -- & -- & $\begin{array}{c}0,713 * * * \\
(0,247)\end{array}$ & -- & -- & $\begin{array}{c}0,840 * * * \\
(0,296)\end{array}$ \\
\hline ADL limitations & -- & -- & $\begin{array}{c}0,434 \\
(0,117)\end{array}$ & -- & -- & $\begin{array}{c}0,405 * * * \\
(0,128)\end{array}$ \\
\hline Child hunger & -- & -- & $\begin{array}{c}0,667 \\
(1,099)\end{array}$ & -- & -- & $\begin{array}{l}-0,202 \\
(0,872)\end{array}$ \\
\hline Adult hunger & -- & -- & $\begin{array}{c}1,453 \\
(0,928)\end{array}$ & -- & -- & $\begin{array}{c}0,526 \\
(0,755)\end{array}$ \\
\hline Poorest household & -- & -- & $\begin{array}{c}0,624 \\
(0,429)\end{array}$ & -- & -- & $\begin{array}{l}0,823 * * \\
(0,376)\end{array}$ \\
\hline Log expenditure per member & -- & -- & $\begin{array}{c}-0,561 * * * \\
(0,112)\end{array}$ & -- & -- & $\begin{array}{l}-0,444 \\
(0,096)\end{array}$ \\
\hline Observations & 7185 & 5505 & 5505 & 4779 & 3761 & 3761 \\
\hline
\end{tabular}

Notes to Table 7. The sample in columns 2 and 5 is restricted to observations with non-missing values on poor health, chronic conditions, ADL limitations, child hunger, adult hunger, poorest household and the logarithm of per capita expenditure. Robust standard errors are presented in parenthesis. Correlation has been allowed between unobservables for individuals living in the same primary sampling unit. Regressions were parenthesis. Correlation has been allowed between unobservables for individuals living in the same primary sampling unit. Regressions were
weighted using post-stratification weights. All regressions included a complete set of indicators for age in years. ${ }^{* * *} \mathrm{p}<0.01,{ }^{* *} \mathrm{p}<0.05,{ }^{*} \mathrm{p}<0.10$.

\section{Discussion}

The NIDS survey is an excellent tool with which to document and, over time, track changes in many aspects of wellbeing in South Africa. Here, we have highlighted the fact that while other surveys can document income or earnings differences by population group or by geographic location, they have been unable to translate these differences into other important scores -such as the depression index. Inequality on income and expenditure appears to be further extended into inequality in domains such as mental health.

To the extent that education is protective of mental health, through all of the channels noted here, it becomes an ever more important focus of public policy: it not only increases economic opportunity, but also improves the mental health of citizens in South Africa. 


\section{References}

Anderson, K, Case, A and Lam, D (2001): "Causes and Consequences of Schooling Outcomes in South Africa: Evidence from Survey Data”, Social Dynamics, 27(1), 37-59.

Case, A and Deaton, A (2009): "Health and Wellbeing in Udaipur and South Africa”, Chapter 9 in Developments in the Economics of Aging, D. Wise (ed.) University of Chicago Press for the NBER.

Case, A and Paxson, C (2005): "Sex Differences in Morbidity and Mortality”, Demography, 42(2), 189-214.

Case, A and Paxson, C (2008): "Height, Health and Cognitive Function at Older Ages”, American Economic Review: Papers and Proceedings, 98(2), 463-467.

Case, A and Menendez, A (2009): "Sex Differences in Obesity Rates in Poor Countries: Evidence from South Africa”, Economics and Human Biology, 7(3), 271-282.

Das, J, Quy-Toan Do, Q, Friedman, J, McKenzie, D and Scott, K (2007): "Mental Health and Poverty in Developing Countries: Revisiting the Relationship”, Social Science and Medicine, 65, 467-480.

Das, J, Quy-Toan Do, Q, Friedman, J and McKenzie, D (2009): "Mental Health Patterns and Consequences: Results from Survey Data in Five Developing Countries", The World Bank Economic Review, 23(1), 31-55.

De Onis, M, Onyango, A, Borghi, E, Siyam, A, Nishida, C and Siekmann, J (2007): "Development of a WHO Growth Reference for School-aged Children and Adolescents", Bulletin of the World Health Organization, 85, 661-668.

Eaton W, Smith, C, Tien, A and Ybarra, M (2004): “Center for Epidemiologic Studies Depression Scale: Review and Revision (CESD and CESDR)” In: Maruish ME (ed.):. The Use of Psychological Testing for Treatment Planning and Outcomes Assessment. 3rd ed. Vol. 3.

Feldman, J J, Makuc, D M, Kleinman, J C and Cornoni-Huntley, J (1989): "National Trends in Educational Differences in Mortality”, American Journal of Epidemiology, 129, 919-1033.

Hoogendijk, W, Lips, P, Dik, M, Deeg, D, Beekman, A and Penninx, B (2008): "Depression Is Associated With Decreased 25-Hydroxyvitamin D and Increased Parathyroid Hormone Levels in Older Adults”, Archives of General Psychiatry, 65(5), 508-512.

Leibbrandt, M, Woolard, I and De Villiers, L (2009): "Methodology: Report on NIDS Wave 1", National Income Dynamics Study Technical Paper No. 1, University of Cape Town.

Long Foley, K, Reed, P S, Mutran, E J and DeVellis, R F (2002): “Measurement Adequacy of the CESD Among a Sample of Older African-Americans”, Psychiatry Research, 109, 61-69.

Patel, V and Kleinman, A (2003): "Poverty and Common Mental Disorders in Developing Countries”, Bulletin of the World Health Organization, 81(8), 609-615.

Radloff L S (1997): “The CES-D scale: A Self-report Depression Scale for Research in the General Population”, Applied Psychological Measurement, 1, 385-401.

Steffick, D E (2000): "HRS Documentation of Affective Functioning Measures in the Health and Retirement Study” Documentation Report DR-005, Survey Research Center at the Institute for Social Research, University of Michigan.

Van de Velde, S, Bracke, P and Levecque, K (2010): "Gender Differences in Depression in 23 European Countries. Cross-national Variation in the Gender Gap in Depression”, Social Science and Medicine, doi:10.1016/j.socscimed.2010.03.035. 
Witoelar, F, Strauss, J and Sikoki, B (2009): "Socioeconomic Success and Health in Later Life Evidence from the Indonesia Family Life Survey” Rand Labor and Population Working Paper Series WR-704. 